\title{
Under the Southern Cross: 13th International Conference on Paleoceanography
}

\author{
Georgina Falster ${ }^{1}$, L. Armbrecht ${ }^{2}$ and L. Missiaen ${ }^{3}$
}

\section{Sydney, Australia, 2-6 September 2019}

Paleoclimate records contain valuable information on long-term climate variability, providing important insights into possible future climate. Producing such records requires collaboration between researchers from many disciplines, including oceanography, climatology, physics, biology, chemistry, and geochronology. Every three years, researchers from these disciplines gather for the International Conference on Paleoceanography (ICP), to share new findings, present methodological advances, and discuss current challenges.

The 13th ICP (icp13.com.au) was held in September 2019 in Sydney, Australia, at the University of New South Wales, and was the first ICP to be held in the Southern Hemisphere. Over 430 delegates - including 140 students - from 31 different countries were warmly welcomed by the Bedegal People, the traditional custodians of this part of Australian country. Twenty-eight students and early-career researchers were awarded travel grants, including six grants awarded by PAGES.

The meeting followed the established ICP format of a small number of invited plenary speakers complemented by dedicated poster sessions. Presentations were grouped according to six main themes, covering new developments in proxies and models, the relationship of paleoclimate with biology and evolution, the carbon cycle, and ocean circulation, with a particular focus on Southern Ocean processes. The 30 plenary talks at ICP13 covered a broad range of topics, including the potential of new and established proxies, using novel numerical methods for improved paleoceanographic reconstructions, the importance of ice-ocean interactions and deep-time studies, and the challenge of bringing together information from proxy data and numerical simulations.

The breadth of paleoceanographic research being undertaken by the community was also reflected in the poster sessions, where approximately 400 posters covered spatial and temporal scales of investigation ranging from local to global, and from days to millions of years, respectively (Fig. 1). These poster sessions provided fertile ground for discussion of new research, which is a key tenet of the ICP.

Plenary talks and posters were supported by four perspective lectures and four special talks. The perspective presentations covered broader aspects of paleoceanography including atmospheric $\mathrm{CO}_{2}$ variability on different timescales, new strategies for modeling complex marine ecosystems, the influence of climate on early human migration patterns, and the degree to which variability in climate proxy data accurately reflects variability in past climates. The special talks included a tribute to the pioneering work of the late Wally Broecker, a demystification of publishing in Nature, and highlights from two ongoing programs: the Australian and New Zealand International Ocean Discovery Program Consortium (ANZIC, iodp.org.au) and the global ocean trace elements program (GEOTRACES, geotraces.org). Throughout the conference, the outstanding quality of research being undertaken by early-career researchers was highlighted by plenary speakers frequently citing ECR contributions to the work being presented. Ten graduate students also earned awards for outstanding poster presentations.

The ICP traditionally encourages social interactions and development of new collaborations, and ICP13 was no exception. Wednesday's conference dinner was held aboard the "Starship Sydney", cruising the picturesque Sydney Harbour. Delegates enjoyed spectacular sunset views of the iconic Opera House and Harbour Bridge - a perfect backdrop for networking. The (in)famous "Paleomusicology" concert featured performances as diverse as the scientific presentations at ICP13, with styles ranging across classical, country, and comedy.

Official pre- and post-conference workshops included meetings of several PAGES working groups (C-SIDE, PAGES Early-Career Network, and CoralHydro2k), as well as the CROCCA2S post-cruise meeting, ICEPRO collaboration meeting, a DeepMIP meeting, and an IODP pre-proposal meeting, along with many unofficial side meetings during which delegates reinforced or built new collaborations within the paleoceanography community. Throughout the week, delegates actively promoted paleoceanography science using the \#ICP13 tag on social media.

Many thanks to the ICP13 organizing committee and sponsors for such an inspiring meeting. Now it's time to look forward to the next ICP, which will be held in Bergen, Norway, from 28 August to 2 September 2022 - don't forget your umbrella! More information at info.icp14@iub.no.

\section{AFFILIATIONS}

Department of Earth and Planetary Sciences,

Washington University in St. Louis, Missouri, USA ${ }^{2}$ Australian Centre for Ancient DNA, The University of Adelaide, Australia

${ }^{3}$ Climate Change Research Centre, University of New South Wales, Sydney, Australia

CONTACT

Georgina Falster: gfalster@wustl.edu 